\title{
Memórias e Representações Sociais da Cidade de Cuiabá, ao Longo de Três Gerações
}

\author{
Memories and Social Representations of Cuiabá Along Three Generations
}

\author{
Ana Rafaela Pecora* a \& Celso Pereira de Sá**b \\ ${ }^{a}$ Universidade Federal de Mato Grosso \& ${ }^{b}$ Universidade do Estado do Rio de Janeiro
}

\begin{abstract}
Resumo
Este estudo analisa as memórias e as representações sociais construídas por três gerações acerca da cidade de Cuiabá, ao longo da segunda metade do século XX. A primeira viveu a juventude durante os anos de 1950 a 1967, quando o progresso da cidade foi vagaroso. A segunda presenciou o início da modernização - 1968 a 1986. A terceira coorte foi contemporânea ao mundo globalizado - 1987 a 2000. Os 150 sujeitos inquiridos compreenderam as seguintes faixas etárias: 65 a 75; 44 a 51; 26 a 33 anos. As evocações livres ao termo indutor "Cuiabá no seu tempo" foram processadas pelo software EVOC e submetidas à análise de similitude. Os resultados revelaram que as representações da cidade permaneceram inalteradas no período investigado.

Palavras-chave: memória social; representações sociais; núcleo central; Cuiabá; geração.
\end{abstract}

\begin{abstract}
This study analyzes the memories and the social representations constructed by three generations concerning the city of Cuiabá during the second half of the $20^{\text {th }}$ century. The first generation lived the youth age during the years 1950 and 1967, when the progress of the city was slow. The second generation witnessed the beginning of modernization from 1968 through 1986. The third generation was contemporary to the globalized world - from 1987 through 2000. The 150 inquired subjects were included in the age bands: 65 through 75; 44 through 51; 26 through 33 years old. The free evocations expressions carried to the inductive term: "Cuiabá in its time". The findings were processed by the software EVOC and submitted to a similitude analysis. The results revealed that the representations of the city had remained unchanged in the investigated mentioned periods.

Keywords: social memory; social representations; central nucleus; Cuiabá; generation.
\end{abstract}

O presente artigo trata dos resultados de uma pesquisa sobre as memórias e representações sociais de três coortes geracionais que viveram sua juventude - faixa etária compreendida entre 15 e 25 anos - na segunda metade do século XX, em Cuiabá, capital do Estado do Mato Grosso, Brasil.

O período acima mencionado é marcado, nas sociedades ocidentais, por muitos conflitos e transformações no campo político, por acelerado desenvolvimento econômico e tecnológico, bem como por modificações sociais e culturais características da sociedade de consumo. Tais ocorrências, segundo Aubert (2004), Charles (2004) e Lipovetsky (2004), contribuíram para uma ampla reconfiguração do panorama contemporâneo.

A segunda metade do século XX desponta, assim, como um rico cenário de investigação no campo da psicologia social. Isto em função de ensejar a exploração da medida

\footnotetext{
* Endereço para correspondência: Universidade Federal de Mato Grosso, Instituto de Educação, sala 65, Av. Fernando Correa da Costa, S/N, Cuiabá, MT, 78060-900. Tel.: (65) 3615 8421. E-mail: arpecora@ terra.com.br ** Endereço para correspondência: Universidade do Estado do Rio de Janeiro, Instituto de Psicologia, Rua São Francisco Xavier, 524, Maracanã, Rio de Janeiro, RJ, 20559-900. Tel.: (21) 2587 7304; Fax: (21) 2587 7284. E-mail: sa.celso@gmail.com
}

em que as transformações políticas, econômicas, tecnológicas, sociais e culturais, deixaram suas marcas no cotidiano das pessoas, em especial no da população juvenil. Contra esse pano de fundo da contemporaneidade ocidental, observa-se que a cidade de Cuiabá foi cenário de um acelerado processo de desenvolvimento na segunda metade do século XX. De fato, nesse período, a cidade saiu de um certo isolamento em relação ao restante do país, devido à precariedade das estradas e dos meios de comunicação, para a condição de importante centro urbano da região Centro-Oeste do país.

O período de 1950 a 2000 foi perpassado em Cuiabá por três distintas coortes geracionais, nos termos de Mannheim (1952/1982), segundo o qual as gerações devem ser definidas mediante o "ritmo e impacto predominantes de mudança social” (p. 94). A primeira delas viveu sua juventude durante os anos de 1950 a 1967, tempo que podemos chamar de calmaria, em que o progresso da cidade ocorreu de forma muito lenta e gradual. A segunda coorte, contudo, experimentou na juventude, 1968 a 1986, o impacto das ocorrências que trouxeram a modernização para a cidade. A terceira coorte é contemporânea à inserção de Cuiabá no mundo globalizado e compreende integrantes que até há bem pouco tempo, de 1987 a 2000, se encontravam no estágio de juventude. 
Estas representações juvenis mais contemporâneas e aquelas que compõem as memórias sociais das gerações precedentes, constituindo o registro psicossocial de como era - ou de como as pessoas se lembram de que era - a cidade no "tempo de juventude" de cada uma delas, são uma forma de descrever o passado de Cuiabá e de seu povo, que se acrescenta à escrita da sua história.

\section{Um Recorte Teórico-Conceitual}

Considerando os propósitos do presente trabalho, optouse por fundamentá-lo sobre construtos teórico-conceituais da memória em uma perspectiva psicossocial (Sá, 2005, no prelo-a, no prelo-b) desenvolvidos a partir das proposições pioneiras do sociólogo M. Halbwachs (1950/1990, 1925/1994) e do psicólogo social F. C. Bartlett (1932/1995), assim como de suas releituras por autores contemporâneos e de aportes de outras disciplinas, como a história e a psicologia cognitiva. A pesquisa é fundamentada ainda, de forma articulada, sobre a teoria psicossocial das representações sociais, que tem em S. Moscovici (1961/1978) seu instituidor, e, em especial, pela abordagem estrutural das representações sociais, devida a J-C. Abric (1998/2000, 2003/2005, 1994/2006).

No que respeita à memória, os autores destacados argumentam que o contexto social é preponderante para a explicação do seu funcionamento na vida cotidiana, não sendo suficiente o estudo das funções psicológicas individuais. Segundo Halbwachs (1950/1990), a memória individual não apenas depende de uma constante referência a "quadros sociais", mas deve ser considerada como um ponto de vista da memória coletiva. Isto implica que nossas lembranças são construídas no âmbito social e se mantêm mediante as trocas e intercâmbios com grupos de pessoas. Nesse sentido, uma condição apontada por Halbwachs, mas também por Bartlett, na consideração da memória é o seu caráter construtivo. As lembranças são reconstruções que se apóiam no passado, mas orientadas em função de necessidades e interesses do presente. Seus conteúdos nunca são, assim, simples reproduções do passado, mas representações construídas a partir deste.

Além desse caráter construtivo, Sá (2005) identifica outros critérios unificadores do campo da memória social, sob o ponto de vista da psicologia social, e o divide em sete instâncias: memórias pessoais, memórias comuns, memórias coletivas, memórias históricas documentais, memórias históricas orais, memórias práticas e memórias públicas. Tais instâncias, como esclarece o autor, não são mutuamente excludentes, mas, ao contrário, interpenetram-se extensamente e podem mesmo algumas se transformar em outras.

No problema de que ora nos ocupamos - as memórias geracionais - a instância privilegiada foi, acompanhando as proposições pioneiras de Mannheim (1952/1982) acerca das gerações, a das memórias coletivas. De fato, são estas que, pela exigência conceitual de uma elaboração grupal, melhor correspondem às experiências formadoras das "unidades de geração", como faz notar o autor:
[...] os jovens que experienciam os mesmos problemas históricos concretos fazem parte da mesma geração real; enquanto aqueles grupos dentro da mesma geração real, que elaboram o material de suas experiências comuns através de diferentes modos específicos, constituem unidades de geração separadas (p. 87).

Não obstante, como o próprio Mannheim admite, os produtos elaborados por tais "unidades de geração" são comumente apropriados pelos jovens daquela "geração real" que se encontram fora do núcleo produtor. Desse modo, é plenamente esperável que as memórias geracionais a serem estudadas sejam em boa parte constituídas por memórias apenas comuns - ou seja, não elaboradas no interior de um grupo - e mesmo por memórias pessoais - que se referem ao passado específico de uma pessoa, mas imerso em sua geração.

No que se refere às representações sociais, cumpre ressaltar inicialmente sua estreita articulação com os estudos de memória social. De fato, como aponta Jedlowski (2000), "a memória coletiva tende a ser entendida pelos sociólogos como o conjunto das representações do passado que um grupo produz, conserva, elabora e transmite através da interação entre seus membros" (p. 125). Essa imbricação entre os dois conceitos é igualmente explorada por Moscovici (1961/1978) e, em especial, pela abordagem estrutural das representações sociais (Abric, 1998/2000, 2003/2005, 1994/2006; Sá, 1996), segundo a qual o núcleo central de uma representação apresenta, dentre outras características, a de ser ligado à memória coletiva e à história do grupo que a construiu.

Extrai-se ainda da abordagem estrutural um importante critério de comparação entre as representações sociais que compõem as memórias das três coortes geracionais, qual seja, o de que elas serão consideradas distintas entre si "se e apenas se" os conteúdos dos seus respectivos núcleos centrais forem significativamente diferentes. Se isto não acontecer, as representações de "Cuiabá", pelas três gerações serão uma e a mesma, embora as experiências pelas quais os seus respectivos membros passaram possam ter sido como certamente o foram - muito diferentes.

Finalmente, justificando a focalização do presente trabalho sobre as memórias dos jovens, conquanto de diferentes épocas, observa-se que, na esteira da caracterização das gerações por Mannheim (1952/1982), vários estudos empíricos, dentre os quais aqueles conduzidos por Conway (1998), têm identificado o intervalo dos 10 aos 25 anos de idade como um bump da memória, uma vez que as experiências que ocorrem durante ele têm se mostrado mais suscetíveis de serem lembradas posteriormente. Segundo Conway, isto se explica porque, ao longo do desenvolvimento individual, o Eu em formação constituiria uma instância privilegiada na codificação e na estruturação do conhecimento autobiográfico e da memória a longo prazo. Ressalta-se, assim, o papel crucial dessa fase de desenvolvimento psicológico, em complexo intercâmbio com as dimensões social, cultural e histórica, na construção das memórias geracionais. 


\section{Método}

\section{Sujeitos}

Os sujeitos da pesquisa são cidadãos que viveram a juventude - aqui delimitada entre os 15 e os 25 anos de idade - em três diferentes épocas da história de Cuiabá a partir de 1950. Estas épocas foram estabelecidas tomando como referência o período de acentuado progresso e modernização da cidade (1968-1986), em confronto com o de relativa estagnação que o antecedeu (1950-1967) e com aquele de consolidação posterior, que vem até o final do século XX (1987-2000).

Os três conjuntos geracionais assim definidos - pelos quais os sujeitos foram igualmente distribuídos - compreendiam, visto que os dados foram coletados em novembro de 2005 a janeiro de 2006, as seguintes faixas etárias: 65 a 75 anos, 44 a 51 anos e 26 a 33 anos.

Para a participação em diferentes etapas da pesquisa, foi recrutado um total de 150 sujeitos, de ambos os sexos, com escolaridade mínima de nível médio completo, dado que pesquisas anteriores (Bosi, 2003) apontam um desempenho mnemônico precário em estratos de escolaridade mais baixa.

\section{Coleta dos Dados}

Os dados foram coletados através de diferentes técnicas, a saber: (a) evocações livres aos termos indutores "a juventude do seu tempo" e "Cuiabá no seu tempo", (b) questionários contendo questões abertas a respeito das recordações sobre as ocorrências que, durante a juventude, imprimiram marcas no cenário sócio-político-cultural local, nacional e mundial importantes para cada geração, e (c) grupos focais, num total de três sendo um para cada coorte - com o propósito de levantar discussão em torno de: "Como foi ser jovem no seu tempo em Cuiabá?".

$\mathrm{O}$ presente artigo trata somente dos dados relativos à associação livre de palavras, de acordo com a técnica proposta por Vergès (1992), coletados junto a 50 sujeitos de cada amostra, com vistas à identificação da estrutura representacional das representações sociais da cidade de Cuiabá construídas pelos três distintos conjuntos etários. Foi, assim, solicitado aos sujeitos que listassem as cinco primeiras palavras ou expressões que viessem de pronto a sua mente quando o termo indutor era proposto. Após este exercício espontâneo, cada sujeito foi convidado a reorganizar as palavras ou expressões evocadas em termos da sua ordem de importância, conforme proposta de Abric (2003/ 2005).

\section{Análise dos Dados}

Segundo a abordagem estrutural das representações (Abric, 1994/2006; Sá, 1996), a pesquisa do núcleo central pode tomar como base dois critérios: (a) a saliência dos elementos da representação; (b) a conexidade entre os elementos da representação.

$\mathrm{Na}$ investigação da saliência dos elementos, os dados foram tratados pelo software EVOC desenvolvido por Vergès (2003), pelo qual os critérios de freqüência e de ordem média de importância (O.M.I) são combinados, de forma a identificar os elementos do sistema central e do sistema periférico das representações.

$\mathrm{Na}$ averiguação da conexidade, aplicou-se a técnica de análise de similitude (Flament, 1986) aos resultados da análise prévia das evocações. Especificamente para a presente pesquisa, estabeleceu-se, com a colaboração de Michel-Louis Rouquette em 2006, um procedimento que consistiu em calcular os índices de similitude entre os próprios elementos que haviam sido mais freqüentemente evocados - e não entre categorias construídas a partir de todos os elementos evocados, como feito por Oliveira e Sá (2001) -, daí resultando uma "árvore máxima", que sintetiza graficamente o conjunto das conexões existentes entre tais elementos.

\section{Cuiabá, na Segunda Metade do Século XX}

A seguir, são apresentados os resultados - quadros de quatro casas e árvores máximas - para os três grupos investigados - Grupo 1 (65-75 anos), Grupo 2 (44-51 anos) e Grupo 3 (26-33 anos) - relativos às representações sociais da cidade de Cuiabá durante os seus respectivos tempos de juventude.

A Figura 1 explicita a estrutura da representação daqueles que viveram sua juventude em Cuiabá durante os anos de 1950 a 1967 (Grupo 1).

\begin{tabular}{l|lll|lll}
\hline \multirow{2}{*}{ Freq. Med. } & O.M.I. $<3$ & Freq. & O.M.I. & O.M.I. $\geq 3$ & Freq. & O.M.I. \\
\hline$\geq 12$ & tranqüila & 29 & 2,586 & boa-para-viver & 23 & 3,087 \\
& menos-violência & 21 & 2,333 & & \\
& todos-se-conheciam & 16 & 2,500 & & & \\
\hline \multirow{3}{*}{12} & & & & cadeiras-calçadas & 9 & 3,222 \\
& pessoas-mais-entrosadas & 10 & 2,500 & distante & 6 & 3,667 \\
& passeios-no-jardim & 8 & 2,875 & pouco-desenvolvida & 6 & \\
& portas-abertas & 6 & 2,833 & & & \\
& família & 5 & 2,400 & & & \\
& pequena & 5 & 2,800 & & & \\
\hline
\end{tabular}

Figura 1. Quadro de quatro casas das evocações livres em relação ao tema "Cuiabá no seu tempo", expresso pelos sujeitos entre 65 e 75 anos. Cuiabá - MT, 2005/2006 (N=50). 
Segundo Sá, Oliveira, Castro, Vetere e Carvalho (no prelo), alguns elementos da primeira periferia, quadrante superior direito, considerando as altas freqüências com que foram evocados, podem ser considerados centrais, na medida em que apresentem, por algum outro critério, como o da conexidade, uma nítida afinidade com elementos do quadrante superior esquerdo. Neste sentido, lança-se a hipótese de que, no presente caso, "boa para viver" possa ser um destes elementos. A análise da conexidade dos elementos evocados, sintetizada na árvore máxima apresentada na Figura $2^{1,}$ vem em apoio a essa hipótese.

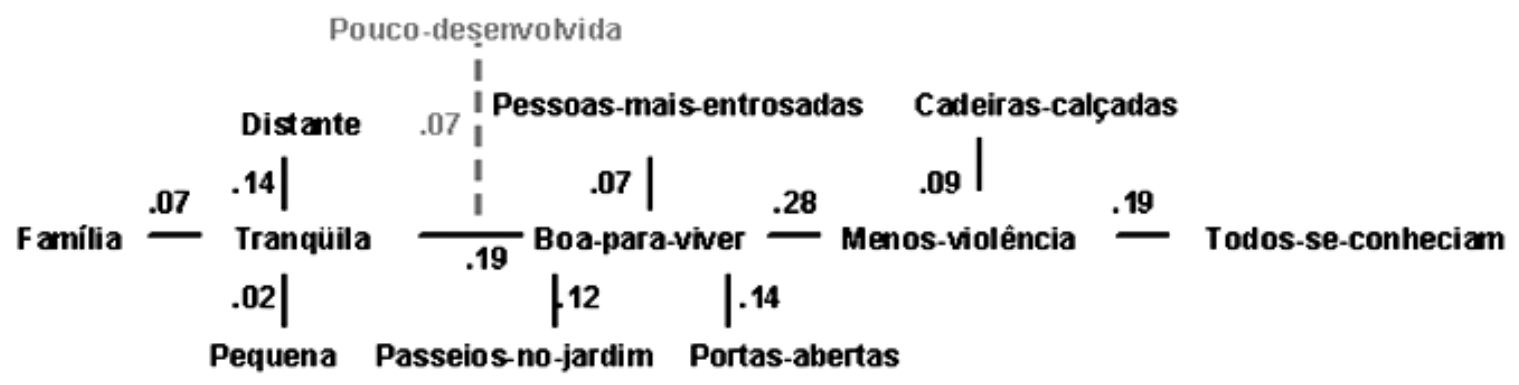

Figura 2. Árvore máxima da análise de similitude das evocações mais freqüentes em relação ao tema "Cuiabá no seu tempo", expresso pelos sujeitos entre 65 e 75 anos. Cuiabá - MT, 2005/2006 (N=43).

Como é possível perceber, a evocação "boa para viver" é a que mais estabelece conexões com as demais, seguida de "tranqüila" e "menos violência", já supostas centrais. Em função da observância deste segundo critério de centralidade - conexidade - passam a ser quatro e não três os elementos centrais da representação de Cuiabá no tempo de juventude dos sujeitos do Grupo 1: "tranqüila", "menos violência", "todos se conheciam" e "boa para viver". Estes elementos retratam Cuiabá de uma época em que o progresso da cidade ocorreu de forma gradual e lenta. Isolada do restante do Brasil e do mundo em função da precariedade dos meios de comunicação e de transporte, a tranqüilidade e a calmaria da cidade, bem como a proximidade entre as pessoas, guardadas na memória da geração que nela então viveu, faz com que Cuiabá da década de 50 e parte da de 60 seja representada como um lugar de agradá- vel moradia, possibilitando tranqüilidade e bom convívio entre as pessoas.

Além disso, os elementos "pessoas mais entrosadas", "passeios no jardim", "portas abertas", "família" e "pequena", situados no quadrante inferior esquerdo, longe de configurarem uma "zona de contraste" em relação à representação majoritária, na verdade a reforçam. O que há, portanto, ao que tudo parece indicar, é uma representação homogênea e compartilhada de forma harmoniosa pelo grupo geracional em questão.

Na seqüência, a Figura 3 apresenta a estrutura representacional de Cuiabá construída por para aqueles que lá viveram sua juventude durante os anos de 1968 a 1986 (Grupo 2), ocasião em que o progresso chega à cidade, retirando Cuiabá da situação de isolamento com o Brasil e o restante do mundo.

\begin{tabular}{|c|c|c|c|c|c|c|}
\hline Freq. Med. & O.M.I. $<3$ & Freq. & O.M.I. & O.M.I. $\geq 3$ & Freq. & O.M.I. \\
\hline$\geq 9$ & $\begin{array}{l}\text { tranqüila } \\
\text { boa-para-viver } \\
\text { segura } \\
\text { todos-se-conheciam } \\
\text { menos-violência }\end{array}$ & $\begin{array}{l}27 \\
15 \\
12 \\
11 \\
11\end{array}$ & $\begin{array}{l}2,222 \\
2,867 \\
2,917 \\
2,545 \\
2,727\end{array}$ & pessoas-mais-entrosadas & 18 & 3,111 \\
\hline$<9$ & $\begin{array}{l}\text { em-desenvolvimento } \\
\text { festas } \\
\text { família } \\
\text { provinciana }\end{array}$ & $\begin{array}{l}8 \\
8 \\
7 \\
6\end{array}$ & $\begin{array}{l}2,875 \\
2,875 \\
2,143 \\
2,667\end{array}$ & $\begin{array}{l}\text { pequena } \\
\text { pouco-desenvolvida } \\
\text { amizades } \\
\text { animada } \\
\text { cadeiras-calçadas } \\
\text { hospitaleira } \\
\text { oportunidades }\end{array}$ & $\begin{array}{l}7 \\
7 \\
6 \\
6 \\
4 \\
4 \\
4\end{array}$ & $\begin{array}{l}3,714 \\
3,571 \\
3,333 \\
3,167 \\
3,250 \\
3,500 \\
3,500\end{array}$ \\
\hline
\end{tabular}

Figura 3 Quadro de quatro casas das evocações livres ao tema "Cuiabá no seu tempo", expresso pelos sujeitos entre 44 e 51 anos. Cuiabá - MT, 2005/2006 (N=50).

${ }^{1} \mathrm{Na}$ Figura 2, cabe esclarecer que a ramificação tracejada e em cinza se refere a mais de uma possibilidade de conexão: o termo "pouco desenvolvida" tanto se conecta a "tranqüila" quanto a "boa para viver", visto que o índice de similitude é o mesmo. Além disso, observe-se que o número de participantes é aí menor - 43 sujeitos - do que o dos que fizeram evocações ( 50 sujeitos). Isto porque cada sujeito só pode participar da análise de similitude caso tenha evocado, no mínimo, dois elementos daqueles constantes do quadro de quatro casas, pois os índices de similitude se referem à co-ocorrência entre dois termos. 
A representação social de Cuiabá pelo Grupo 2 tem como elementos centrais os termos "tranqüila", "boa para viver", "segura", "todos se conheciam" e "menos violência". Com exceção de "segura", eles são idênticos aos elementos centrais do Grupo 1. Isto quer dizer que o progresso e o desenvolvimento da cidade não parecem ter sido suficientes para ensejar a produção de uma representação diferente pela nova geração.

A árvore de similitude mostrada na Figura 4, ao ter o elemento "tranqüila" como centralizador das conexões, reforça a análise anterior, segundo o qual Cuiabá continua ser representada como lugar de sossego, com violência distante e de bom convívio entre as pessoas.

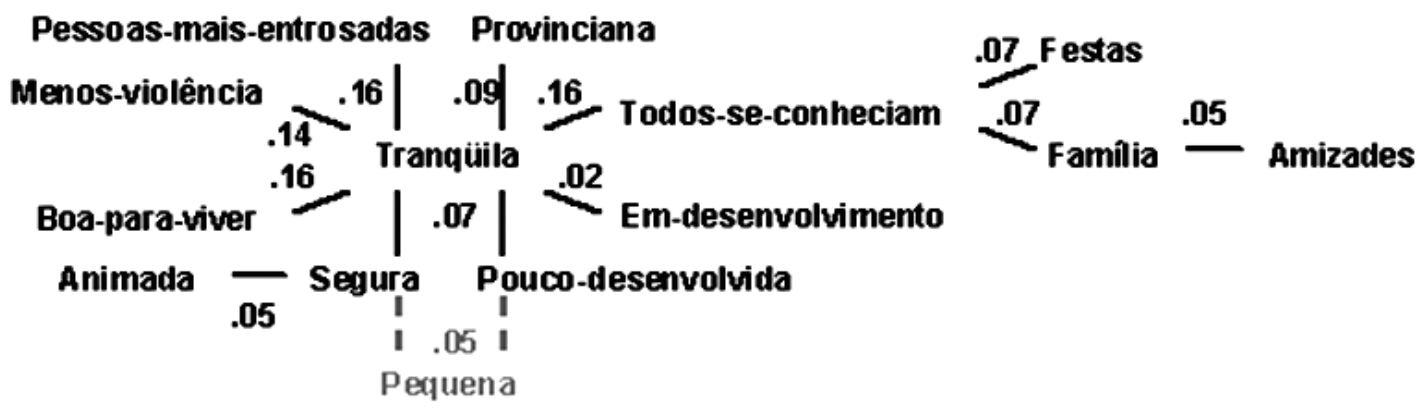

Figura 4. Árvore máxima da análise de similitude das evocações mais freqüentes em relação ao tema "Cuiabá no seu tempo", expresso pelos sujeitos entre 44 e 51 anos. Cuiabá - MT, 2005/2006 (N=43).

Dois dos elementos situados na "zona de contraste" "em desenvolvimento" e "festas" - parecem de fato contrastar com os do núcleo central. A atribuição de importância à evocação "em-desenvolvimento" pode indicar a existência de um subgrupo - ou uma unidade de geração particular no interior da geração global, no entender de Mannheim (1952/1982) - que, para além de considerar as vantagens de uma cidade pequena e isolada, apreciava as transformações que estavam nela ocorrendo. Da mes- ma forma, a importância atribuída a "festas" - pelo mesmo ou por outro subgrupo - acrescenta uma certa nota de agitação na representação de uma Cuiabá essencialmente tranqüila.

A Figura 5 apresenta o quadro de quatro casas relativo à representação de Cuiabá na última década do século passado construída pelo conjunto geracional que então de 1987 a 2000 - viveu a sua juventude (Grupo 3).

\begin{tabular}{|c|c|c|c|c|c|c|}
\hline Freq. Med. & O.M.I. $<2,9$ & Freq. & O.M.I. & O.M.I. $\geq 2,9$ & Freq. & O.M.I. \\
\hline \multirow{5}{*}{$\geq 11$} & tranqüila & 17 & 2,353 & & & \\
\hline & todos-se-conheciam & 15 & 2,667 & & & \\
\hline & menos-violência & 15 & 1,867 & & & \\
\hline & boa-para-viver & 13 & 2,846 & & & \\
\hline & pessoas-mais-entrosadas & 11 & 2,455 & & & \\
\hline \multirow{3}{*}{$<11$} & em-desenvolvimento & 9 & 2,778 & animada & 10 & 2,900 \\
\hline & hospitaleira & 6 & 2,667 & pouco-lazer & 8 & 3,125 \\
\hline & turma-de-jovens & 6 & 2,667 & provinviana & 6 & 3,333 \\
\hline
\end{tabular}

Figura 5. Quadro de quatro casas das evocações livres ao tema "Cuiabá no seu tempo" expresso pelos sujeitos entre 26 e 33 anos. Cuiabá - MT, 2005/2006 (N=50).

O núcleo central da representação do Grupo 3, com idades entre 26 e 33 anos, mantém os mesmos termos já explicitados pelos grupos anteriores, acrescidos de "pessoas mais entrosadas", o que permite já concluir por uma significativa estabilidade intergeracional da representação social de Cuiabá. A árvore máxima, na Figura $6^{2}$, reforça tal conclusão, visto que o termo "tranqüila" permanece como o elemento que mais faz conexão com os demais. 
Turmas-de-jovens

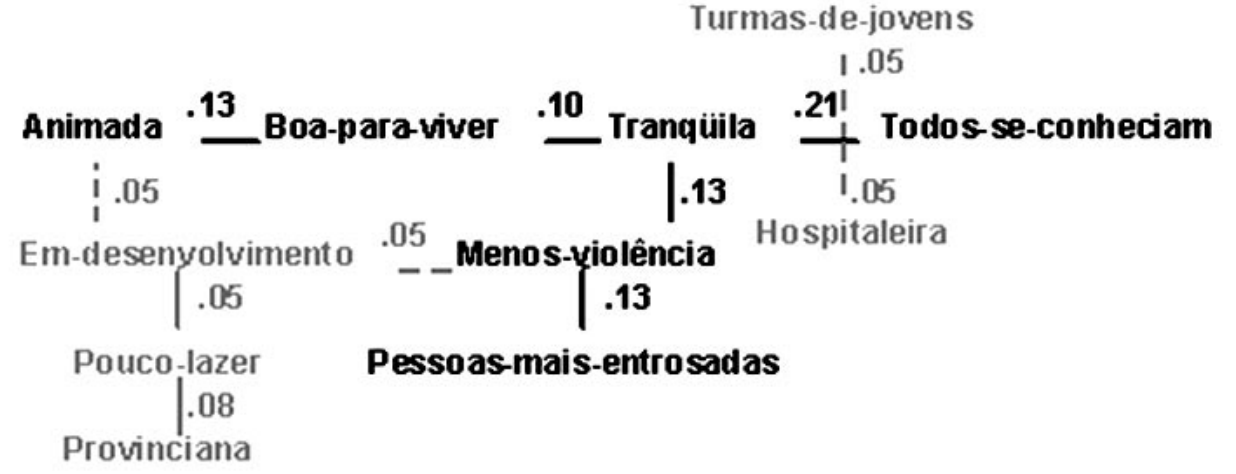

Figura 6. Árvore máxima da análise de similitude das evocações mais freqüentes em relação ao tema "Cuiabá no seu tempo", expresso pelos sujeitos entre 26 e 33 anos. Cuiabá - MT, 2005/2006 (N=39).

\section{Conclusão}

Segundo a abordagem estrutural das representações sociais, aqui privilegiada, as representações de dois ou mais conjuntos sociais acerca de um mesmo objeto só podem ser consideradas diferentes se as composições dos respectivos núcleos centrais forem nitidamente diferentes. Se isto não se verifica, há que se concluir que se trata da mesma repre- sentação social básica, apenas diversamente ativada em função das situações específicas em que se encontram os diferentes grupos de sujeitos. Nesse sentido, os resultados da presente pesquisa evidenciam a existência de uma representação única de "Cuiabá no meu tempo" por parte das três coortes geracionais investigadas, visto que as diferenças apresentadas por elas em nível central são mínimas e absolutamente não contraditórias, como mostra a Figura 7.

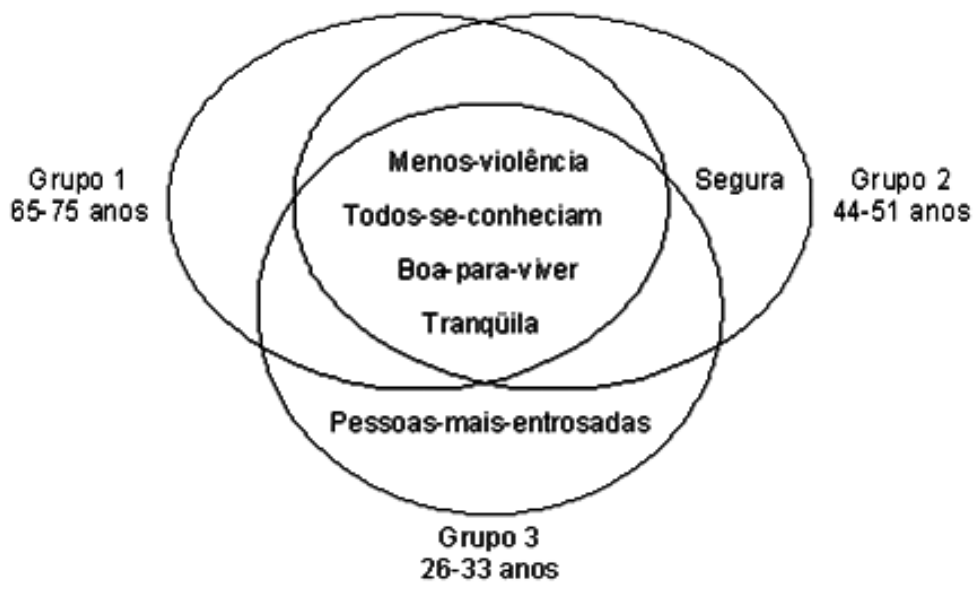

Figura 7. Comparação global dos núcleos centrais ao tema "Cuiabá no seu tempo", expresso pelos três grupos de sujeitos. Cuiabá - MT, 2005/2006 (N=150).

De acordo com a abordagem privilegiada neste estudo, considerando que os núcleos centrais são muito semelhantes, aquilo que caracteriza distintivamente o "meu tempo" de cada uma das gerações é representado perifericamente. Assim, um exame comparativo dos elementos das "zonas de contraste" e das " 2 as periferias" das respectivas representações, como mostrados nas Figuras 1, 3 e 5, lança alguma luz sobre as diferenças entre as três memórias geracionais. Como já apontado anteriormente, apenas uma fração dos sujeitos do Grupo 2 confere importância ao elemento "festas", que assim contrasta com a tranqüilidade evocada pela maioria, mas não deixa de receber algum endosso da evocação periférica de "animada" e "amizades". Destaca-se ainda na "zona de contraste" da representação desse Grupo 2 o elemento "em desenvolvimento", que, na "2a periferia", é reforçado pela evocação de "opor- tunidades", mas tem ainda que coexistir com a consideração de que Cuiabá é "pequena", "provinciana” e "pouco desenvolvida". Já no Grupo 3, além de que uma fração contrastante de sujeitos continue a insistir em que a cidade se encontra "em desenvolvimento", esse julgamento não é mais desacreditado pela periferia, que apenas admite a persistência de um caráter provinciano. Dando seqüência a uma relativa quebra da tranqüilidade característica de Cuiabá, iniciada pelo Grupo 2, o Grupo 3 traz em sua "zona de contraste" o elemento "turmas de jovens", que repercute perifericamente através da evocação de "animada", mas com "pouco lazer", o que talvez tenha sido a causa da formação daquelas turmas.

As diferenças assinaladas nos parágrafos precedentes não chegam, entretanto, por seu reduzido escopo, a desautorizar a conclusão geral de que, embora a cidade tenha se desen- 
volvido e recebido um elevado contingente migratório durante os 50 anos considerados, a sua representação contemporânea pelas gerações que então se sucederam é uma e a mesma. A história de Cuiabá registra por certo a ocorrência de importantes mudanças durante aquele período, mas a memória - aqui entendida como um conjunto de representações do passado - e a história não são a mesma coisa, como, dentre outros, aponta Lavabre (1994):

Evidenciar a memória não é, portanto, descobrir todo ou parte do passado, mas a presença - sempre incerta do passado e, mais precisamente ainda, a presença sempre incerta - não do passado tal como ocorreu, mas a impressão que essas 'coisas que passaram' deixaram ao passar. Primeiro elemento de definição, pois, que nos permite alcançar o essencial: a memória não restitui de maneira nenhuma o passado, ela não o reproduz, ela não o estabelece, ela nos dá a ver ou entender apenas o 'presente do passado' (p. 40-41).

Concluindo, os tempos passados - necessariamente diversos - vividos pelas diferentes gerações acabaram por ser representados sob uma versão única no presente, ensejada talvez por um sentimento comum de nostalgia em relação à Cuiabá do tempo de juventude, mesmo que com cenários originais diferentes. É possível ainda que tal representação comum seja sistematicamente alimentada pela mídia e pelas comemorações, com uma ênfase sobre os primeiros tempos, mais distantes, e mesmo pelos processos mais informais de transmissão intergeracional da memória, daí resultando a constituição de uma representação hegemônica (Arruda, 1998; Moscovici, 1961/1978; Wagner, 1998) de Cuiabá, que se impõe à maciça maioria dos cuiabanos, independentemente de suas diferenças em idade e experiências passadas.

\section{Referências}

Aubert, N. (2004). Introdução. In N. Aubert (Ed.), L'individu hypermoderne (pp. 7-9). Ramonville Saint-Agne, France: Érès. Abric, J-C. (2000). A abordagem estrutural das representações sociais. In A. S. P. Moreira \& D. C. Oliveira (Eds.), Estudos interdisciplinares de representações sociais (pp. 27-38). Goiânia, GO: AB. (Original publicado em 1998)

Abric, J-C. (2005). Le recherche du noyau central et de la zone muette des représentations sociales. In J-C. Abric (Ed.), Méthodes d'étude des représentations sociales (pp. 59-80) Paris: Éditions érès. (Original publicado em 2003)

Abric, J-C. (2006). Methodologie de recueil des représentations sociales. In J-C. Abric (Ed.), Pratiques sociales et représentations (pp. 59-82). Paris: Presses Universitaires de France. (Original publicado em 1994)

Arruda, A. (1998). O ambiente natural e seus habitantes no imaginário brasileiro. In A. Arruda (Ed.), Representando a alteridade (pp. 17-46). Petrópolis, RJ: Vozes.

Bartlett, F. C. (1995). Remembering: A study in experimental and social psychology. Cambridge, MA: Cambridge University Press. (Original publicado em 1932)

Bosi, E. (2003). O tempo vivo da memória: Ensaios de psicologia social. São Paulo, SP: Ateliê.

Charles, S. (2004). O individuo paradoxal: Introdução ao pensamento de Gilles Lipovetsky. In G. Lipovetsky \& S. Charles
(Eds.), Os tempos hipermodernos (pp. 11-48). São Paulo, SP: Barcelona.

Conway, M. A. (1998). El inventario de la experiencia: memoria e identidad. In D. Páez, J. F. Valencia, J. W. Pennebaker, B. Rimé \& D. Jodelet (Eds.), Memorias colectivas de procesos culturales y políticos (pp. 49-82). Bilbao, España: Universidade del País Vasco.

Flament, C. (1986). L'analyse de similitude: une technique pour les recherches sur les representations sociales. In W. Doise \& A. Palmonari (Eds.), L'étude des représentations sociales (pp. 139-156). Paris: Delachaux et Niestlé.

Halbwachs, M. (1990). A memória coletiva. São Paulo, SP: Vértice. (Original publicado em 1950)

Halbwachs, M. (1994). Les cadres sociaux de la mémoire. Paris: Albin Michel. (Original publicado em 1925)

Jedlowski, P. (2000) La sociología y la memoria colectiva. In A. Rosa, G. Bellelli \& D. Bakhurst (Eds.), Memória colectiva e identidad nacional (pp. 123-134). Madrid, España: Biblioteca Nueva.

Lavabre, M. C. (1994). Etre histoire et mémoire: à la recherche d'une méthode. In J. C. Martin (Ed.), La Guerre Civile entre histoire e memoire (pp. 39-47). Nantes, France: Ouest Éditions.

Lipovetsky, G. (2004). Tempo contra tempo, ou a sociedade hipermoderna. In G. Lipovetsky \& S. Charles (Eds.), Os tempos hipermodernos (pp. 11-48). São Paulo, SP: Barcelona.

Mannheim, K. (1982). O problema sociológico das gerações. In M. M. Foracchi \& F. Fernandes (Eds.), Karl Mannheim: Sociologia (pp. 67-95). São Paulo, SP: Ática. (Original publicado em 1952)

Moscovici, S. (1978). A representação social da psicanálise. Rio de Janeiro, RJ: Zahar Editores. (Original publicado em 1961)

Oliveira, D. C., \& Sá, C. P. (2001). Representações sociais da saúde e doença e implicações para o cuidar em enfermagem: Uma análise estrutural. Revista Brasileira de Enfermagem, 54(4), 608-622.

Sá, C. P. (1996). Núcleo central das representações sociais. Petrópolis, RJ: Vozes.

Sá, C. P. (2005). As memórias da memória social. In C. P. Sá (Ed.), Memória, imaginário e representações sociais (pp. 6386). Rio de Janeiro, RJ: Museu da República.

Sá, C. P. (no prelo-a). Sobre o campo de estudo da memória social: Uma perspectiva psicossocial. Psicologia: Reflexão \& Crítica.

Sá, C. P. (no prelo-b). Les défis d'une psychologie sociale de la mémoire. Maison des Sciences de l'Homme.

Sá, C. P., Oliveira, D. C., Castro, R. V., Vetere, R., \& Carvalho, R. V. C. (no prelo). A memória histórica do Regime Militar ao longo de três gerações, no Rio de Janeiro: Sua estrutura representacional. Estudos de Psicologia (Campinas).

Vergès, P. (1992). L'évocation de l'argent: une méthode pour la definition du noyau central de la représentation. Bulletin de Psychologie, 45(405), 203-209.

Vergès, P. (2003). EVOC - Ensemble de programmes permettant l'analyse des évocations: manuel version 15 octobre 2003. Aix-en-Provence, France: LAMES.

Wagner, W. (1998). Sócio-gênese e características das representações sociais. In A. S. P. E. Moreira \& D. C. Oliveira (Eds.), Estudos interdisciplinares de representação social (pp. 03-25). Goiânia, GO: AB. 